\title{
Inequality and locational determinants of the distribution of living standards in India
}

\author{
Rishabh Kumar ${ }^{1}$, Sriram Balasubramanian ${ }^{2}$, and Prakash \\ Loungani $^{3}$ \\ ${ }^{1}$ Corresponding author, University of Massachusetts Boston , \\ Email: Rishabh.Kumar@umb.edu \\ ${ }^{2}$ International Monetary Fund \\ ${ }^{3}$ International Monetary Fund
}




\begin{abstract}
We analyze consumption distribution in India purely on the basis of location - a combination of the state and sector (urban, rural) - and find that it explains a third of the variation in living standards. Consumption is also shown to be positively related to locational inequality. The main reason is that in poorer locations, consumption is tightly (less unequally) distributed around a low level, making class a poor predictor of higher living standards compared to the aggregate. In effect, from an individual's perspective, living standards are higher in richer, but more unequal, locations in India. We analyze these paradoxes as evidence of an ongoing Kuznets type processes. Our results have implications for the persistence of economic migration within a fast-growing emerging economy. Individuals can choose to change their location to enjoy better living standards, but not necessarily trade other social, or individual predictors, like caste, religion and gender.
\end{abstract}

Keywords: India, Inequality, Kuznets curve, Structural change, Gini, Migration, Consumption 


\section{Context}

In 2011-12, the average income in one of the poorest states in India (Bihar) was around 13 percent of the corresponding figure for the national capital (New Delhi), measured using State Gross Domestic Product (SGDP) per capita. India is in general poor by global standards, with per-capita incomes just under a third of the world average. However, the magnitude of within-India differences in per-capita income is as large as the ratio of GDP per capita ${ }^{1}$ between India, and an advanced country like the USA. Note that most Indian states are highly populous; at a level comparable to major countries. Bihar, for example, has greater population than all but fifteen countries. But, a resident of Bihar who makes five times the average income is still poorer than someone who makes the average income in Delhi. We center our paper on these large locational differences within India, using one basic question: how much interpersonal variation in Indian living standards can be explained solely based on differences across differences across locations?

To be clear, living standards vary across India for a number of reasons. Like the case for most major economies in the twenty first century, India has very high income and wealth inequality (Alvaredo et al., 2018). Equality of opportunity is strongly dependent on social groups like caste, gender and religion (Munshi and Rosenzweig, 2009; Asher et al., 2018). The question we pose is different, much simpler and evaluates the "premium" that location gives to individuals. Large differences in per-capita income between different locations (for any number of

\footnotetext{
${ }^{1}$ Measured using 2011 PPP dollars, according to the World Bank Open Database, India's GDP per capita was 4,493 versus 49,886 for the USA. See: https://data.worldbank.org/indicator/NY.GDP.PCAP.PP.CD?locations=US-IN
} 
economic and historical reasons), can potentially supersede differences due to class or social groups within those locations. In a seminal paper, Milanovic (2015) showed that over two-thirds of variation in global incomes is explained by location alone. Basically, interpersonal differences amongst individuals are a function of the level and distribution of income, which are allocated at birth ${ }^{2}$ and which cannot be changed by the actions of the individual alone.

We apply Milanovic's location framework and apply it to India, exploiting heterogeneity in per-capita incomes across states. Meanwhile, there are no constraints on migration within sovereign boundaries so that, if location predicts interpersonal consumption differences, individuals face a real choice: expend effort to improve class position where they are located, or change location itself to be allocated a potentially higher living standard with even a downgrade in class position. We define location at the level of individual states divided into urban and rural substates. In our main model, for $\mathrm{N}$ states, we construct $2 \mathrm{~N}$ locations. That is, we divide India into $\mathrm{N}$ rural states and $\mathrm{N}$ urban states but with $\mathrm{N}$ (state-level) per-capita incomes and $2 \mathrm{~N}$ levels of consumption inequality. The main reason is that all the dynamism in consumption inequality occurs in urban India through the 1990s and 2000s (Subramanian and Jayaraj, 2015), consistent with a Kuznets process. While urban growth stagnated in several states (Deaton and Dreze, 2002), creating variation in urban outcomes at the state level, there is also an acceptance in the literature on the role ${ }^{3}$ played by the urban sector in aggregate poverty re-

\footnotetext{
${ }^{2}$ At the global level, most individuals are stuck with such outcomes given that 97 percent of the world's population resides in the country in which they are born.

${ }^{3}$ Datt et al. (2020) argue that urbanization, while lacking within-sector distribution neutrality, has been consistent with a Kuznets process and a critical reason for the decline of headcount
} 
duction.

Using nationally representative survey data on consumption (a proxy for living standards), our main finding is that almost a third of the variation in living standards can be predicted by location, as per our aforementioned definition. As expected, richer states predict higher consumption levels. However, reversing the finding of Milanovic at the global level, we find that locational inequality is positively related to expected consumption levels in India. In fact, the gains from one additional unit of inequality (measured in terms of Gini indices) are higher than gains from being in a state with higher literacy rates. Structural factors, like statelevel manufacturing (or services) output shares matter much less. One possible explanation maybe that economic dynamism has long become concentrated in a few large cities in India, which swing our result in this direction.

We explore multiple aspects of location and development in India to substantiate our results. Ultimately, our estimates show that an economic migrant can (on average) expect to be better off in the lower classes of urban India than being in the upper middle class of rural India. Our analysis offers some basis for the very large flow of inter-state rural to urban migration - according to the 2017 Economic Survey of India, and the 2011 census, 9 million individuals migrate annually India and 139 million out of 1.3 billion strong population ${ }^{4}$ are migrants. Fitted to our framework, this is a paradox of absolute versus relative gains, with the former

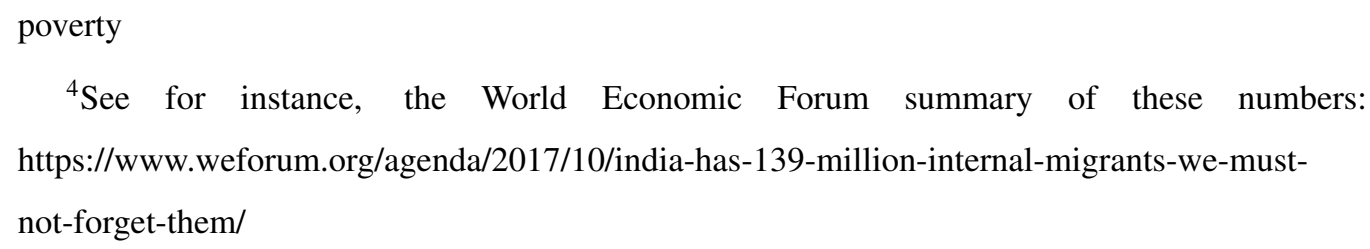
https://www.weforum.org/agenda/2017/10/india-has-139-million-internal-migrants-we-mustnot-forget-them/ 
trumping the latter, and underpinning the uncomfortable challenge in of inclusive growth in a developing economy. Interestingly, when we use wealth as the dependent variable, our model loses predictive power and locational inequality also becomes insignificant. The upshot is that location influences economic variables with "quick" returns like consumption but not slow moving variables like household wealth. To the best of our knowledge, our analysis is the first instance of explaining consumption variation in India using this methodology. The existing literature has mostly tried to measure evolution of inequality among various social groups like caste, gender, education levels etc (Subramanian and Jayaraj, 2015), or tried to explain it because of individual characteristics (Kumar et al., 2019).

One constraint we face is the lack of more recent data. 2011-12 is the last public release of "thick" consumer expenditure surveys conducted by the erstwhile National Sample Survey Organization (NSSO) ${ }^{5}$. However, our dataset still captures the effects of an important policy innovation in rural India - namely, the rural job guarantee ${ }^{6}$ (MGNREGA). Our results therefore are further enforced by the fact that this historic wage stimulus is not sufficient to flip the urban-rural gap in living standards. Given lack of data, social scientists have begun drawing on so-called nationally representative consumption data published for more recent

\footnotetext{
${ }^{5}$ The findings of a more recent 2017-18 NSSO consumption survey were leaked in the press recently, however no microdata is available for public use, hence we have chosen to restrict our data till 2011-12. In the meantime, consumption data have been released as within wage and unemployment surveys though these focus on the labor force.

${ }^{6}$ The Mahatma Gandhi National Rural Guarantee Act is a rural job guarantee act passed in 2005 and applicable to all districts of India as of 2008. It guarantees 100 days of annual employment (at minimum wages) to every rural household in proximity to their location
} 
years by the Centre for Monitoring Economy (CMIE). For our purpose, this data is not suitable as outlined in a recent critique ${ }^{7}$ (Somanchi, 2021) because CMIE's survey design is strongly biased towards better-off households. To be clear, our analysis is simple, staying focused on the role of location for explanation and to reflect the distribution of consumption it is imperative that we have sufficient representation of the poor. Our variables are aggregative by design - we aggregate individual units into percentiles and use macro-variables like per-capita income, literacy, sectoral output shares etc as explanatory variables which cannot be influenced by an individual.

\section{Concepts and data sources}

India's official statistical authorities collect two major ${ }^{8}$ household unit surveys - namely, the Consumer Expenditure Survey for consumption and the All India Debt and Investment Survey for wealth. These surveys are conducted separately so that households cannot be matched across datasets and one cannot relate capital accumulation and living standards for the same households. We do however use the AIDIS survey (2011-12) for separate tests. Our main cross-sectional data source is the 2011-12 release (68th round) of the NSSO Consumer Expenditure Survey. We use micro-data from this nationally representative survey to calculate

\footnotetext{
${ }^{7}$ See also Jean Dreze and Anmol Somanchi - "New barometer of India's economy fails to reflect deprivations of poor households. Economic Times (June 21, 2021). https://economictimes.indiatimes.com/opinion/et-commentary/view-the-new-barometer-ofindias-economy-fails-to-reflect-the-deprivations-of-poor-households/articleshow/83696115.cms"

${ }^{8}$ Other datasets published by NSSO are either focused on health, or daily wages of workers.
} 
annual per capita consumer expenditure using monthly expenditure information - our indicator of living standards. The survey covers representative populations from rural and urban India across all states (although sample sizes vary across states).

To measure time series on consumption, we utilize the World Bank's PovCalNet database. For India, PovCalNet uses the NSSO surveys to merge and standardize distribution information with other worldwide surveys; thereafter these data are used for measurement of global poverty. Consumption spending figures in PovCalNet are provided only at decile levels of the distribution. Each year of data can be disaggregated at the national, rural or urban level. The advantage of using data in this version is that they permit computing decile-wise growth rates over time and comparison with two other high growth, emerging, Asian economies - China and Indonesia - who also produce consumption surveys. The PovCalNet metric for these two countries is also based on consumption surveys, thereby making comparison appropriate. These consumption data are in 2011 PPP Dollars, jointly covering at least 1983-2011/12 for India, China and Indonesia. PovCalNet further divides these three countries into rural and urban sub-countries owing to their large (particularly rural) populations. Price indices are calculated ${ }^{9}$ separately to account for differences in the cost of consumption in urban regions, as opposed to the rural countryside. Thus, any divergence in urban and rural growth reflects more than simply the cost of living such as (say) due to housing rents.

\footnotetext{
${ }^{9}$ See http://iresearch.worldbank.org/PovcalNet/methodology.aspx for the methodology underlying PovCalNet price indices. Because cost of living may be less in rural India than urban India, the PPP is separately calculated and built into all welfare measures
} 
Does consumption expenditure serve as a good approximation of living standards? Our basic assertion is that it is at least appropriate. While we would prefer to have unit-level income data - or even, joint distributions of income and consumption, the official authorities in India do not conduct income surveys. Accordingly, India's poverty rate ${ }^{10}$ is officially measured using consumption data. Second, income, even if available, would itself capture living standards imperfectly. A vast majority of the adult population that earns wages, for instance, is employed either in rural agriculture or in the informal sector where measurement would be problematic due to seasonality, self-employment or precarity. Less than 5 percent of the adult population is captured by the income tax ${ }^{11}$ code (Chancel and Piketty, 2019) and the agricultural sector is exempt from direct income taxes anyway. Point being, income and consumption are both concepts rendered with their own imperfections. For our purpose, we can say, at least, that consumption (on average) improves when one has more income to spend, thereby proxying variation in living standards. For example, Pandey et al. (2020) show that crosssectional variation in food consumption closely reflects income differences across India.

\footnotetext{
${ }^{10}$ See for example the discussion on the use of NSSO consumption expenditures for poverty in Subramanian (2011).

${ }^{11}$ This also makes the use of income tax returns data inappropriate for studying inequality for the broad population. The income tax authorities publish tax returns in tabulated form (lacking unitlevel information), which are most suitable for studying the upper tail of the income distribution (Top 5 percent at most). These data itself went unpublished between 2000 and 2012, the period of highest economic growth in India. This may be one reason why studies using consumption to study growth and inequality proliferated after the 2000s.
} 
One valid concern about using consumption to measure inequality of living standards is that consumption inequality tends to be less than income inequality, both theoretically and empirically. The point being, consumption data may understate the actual variation in living standards. In economic theory, consumption is a function of income but given that the rich have a high propensity to save, the upper tail of income tends to be more widely dispersed. Empirically, there is little doubt that consumption inequality in India is biased downward. For example, the Indian Gini for consumption (from surveys) is usually estimated in the range of 0.3 to 0.4 , whereas in theory, if incomes are distributed in a parameter-free exponential form, then the Gini should be closer to 0.5 (Kumar, 2017). A commonly cited explanation is that the NSSO misses the consumption of the rich (in the upper tail). This has resulted in a large literature ${ }^{12}$ about the growing gap between consumption growth ${ }^{13}$ measured in the national accounts versus national surveys.

Still, from our perspective, as long as we have some coverage of the upper tail, missing consumption of the very rich is not detrimental ${ }^{14}$ to our results. What we require is adequate representation of the vast majority, especially the poor, which consumption surveys represent better than other available data for India in this period. Reassuringly, the functional form for consumption data agrees

\footnotetext{
${ }^{12}$ See Subramanian and Jayaraj (2015).

${ }^{13}$ Another important part of this puzzle (diverging survey and NAS consumption) is that national accounts impute owner-occupied rents and these adjustments bias living standards upwards compared to “on the ground realities." See Sundaram and Tendulkar (2003) and Deaton and Kozel (2005)

${ }^{14}$ As is the case with most survey data, topcoding and non-response rates limit knowledge about the upper tail in any case. This is further substantiated in Sundaram and Tendulkar (2003)
} 
with the expected distribution of incomes. The bulk of the population fits a lognormal/exponential distribution and the upper tail (90th percentile onwards) in survey data follows a Pareto-type power law distribution $\left(R^{2}=0.99\right)$. Such twoclass distributions are statistical regularities in cross-country consumption and income data (Chakrabarti et al., 2018). We estimated a Pareto coefficient ( $a$ ) of 2.5, which implies a well defined ${ }^{15}$ mean and variance $(a>2)$.

From statistical appropriateness, we address whether consumption can conceptually reflect living standards ${ }^{16}$ well enough. The core issue here is that development and structural change transforms patterns of consumption itself. For example, in India, there is a well documented disconnect between average calorie intake and consumption per-capita. Deaton and Drèze (2009) showed that average calorie intake declined between 1983 and $2005^{17}$ despite an increase in consumption and income per-capita. Several explanations have been offered - declining calorie requirements due to labor saving technical change, or food budget squeeze in light of informality and expenditures on privatized goods (Basole and Basu, 2015a). Either way, the consumption of Indians has grown primarily due to non-food ex-

\footnotetext{
${ }^{15} \mathrm{~A}$ further shortcoming of using income distribution in regression analysis is that the upper tail has a Pareto of 1.5-1.8 (Kumar, 2017), which means its variance is undefined.

${ }^{16}$ Conceptually, another excellent definition of living standards uses caste-specific measures (Deshpande, 2001). Given deprivation in India gets allocated at birth, due to caste immobility, this is an alternative to standard consumption measures. While this is important in studying social inequality, our analysis is less social group specific, hence we limit ourselves to naive consumption only.

${ }^{17}$ Basole and Basu (2015a) extend this series to 2010 and also review explanations in the literature for the calorie puzzle.
} 
penditure and thus, the correspondence between living standards and consumption should be understood by reducing the weight on food consumption. This would be consequential were we to focus on inter-temporal comparison of consumption between different classes. However, we restrict our analysis to the 2011-12 crosssection. But, we acknowledge, as others show (Basole and Basu, 2015b), that variation in living standards weighs non-food consumption more emphatically.

\section{Stylized facts about consumption in India}

Our paper follows a rich tradition of analysis of inequality in India using consumption survey data. The primary reason our analysis differs is because we use location as a sole predictor of consumption, abstaining from previously studied issues like education, social hierarchies etc. As we mentioned previously, lack of data on incomes (especially for the poor) has led to a dependence on consumption as a measure of inequality and growth. There is general agreement that inequality increased in India during the 1990s; one often cited reason is the creation of winners and losers, due to trade liberalization in 1991, without a redistributive mechanism to transfer gains downwards (Topalova, 2007). The best known analysis of trends in inequality derives from Deaton and Dreze (2002) who established growing inequality in the 1990s, driven by the gap in urban-rural consumption and a growing consumption gap between states (poor states basically never took off). Subramanian and Jayaraj (2015) used "centrist" measures of inequality, analyzing data up to the 2009 survey, to show that while overall consumption inequality has increased, rural inequality has not (statistically). 
Another important point to consider here is that spatial (state and sector) patterns may reflect forces moving in directions that are not necessarily in line with social dynamics. For instance, within rural areas, inequality may be static but it may hide growing within-group patterns of inequality; especially because the composition of groups tends to change over time. This is especially the case in India due to caste based organization of society. Subramanian and Jayaraj (2015) show that for all castes, within-group inequality has increased and is highest in the top castes in the social hierarchy. Kumar et al. (2019) document the same pattern, with consumption inequality between castes also showing an increase between 1993 and 2009, and stratification in the non-SC/ST caste group. We feel it is important to outline these social inequalities because while we intentionally abstain from any individual level determinant of consumption (like caste, education etc), they constitute a defining element of inequality and mobility in India.

\subsection{Rural and urban consumption}

We quickly summarize the main facts to bring the general reader up to speed on the analysis that follows. Figure 1 compares two ends of the distribution (top 10 percent and bottom 40 percent), also disaggregated for rural and urban India. At national, rural and urban levels, consumption shares of the poor mostly remained stable between 8-10 percent between 1983 and 2011. For the rich (the top decile), there were noticeable shifts in consumption. In rural India, the share of the rich came down slightly while there was divergence between the poor and rich (the rich gained slightly) in urban India. Naturally, the upshot is that any consumption gains or losses for the richest decile came primarily at the expense of the middle class (40th to 90th percentiles) and national trends reflect a growing bias due to 
the urban population's consumption; the top decile gains slightly in consumption over 1983-2011. Note that national trends in consumption shares reflect not just the rise of urban consumption inequality, but also the effects of urbanization ${ }^{18}$ over this period.

India: top and bottom consumption shares

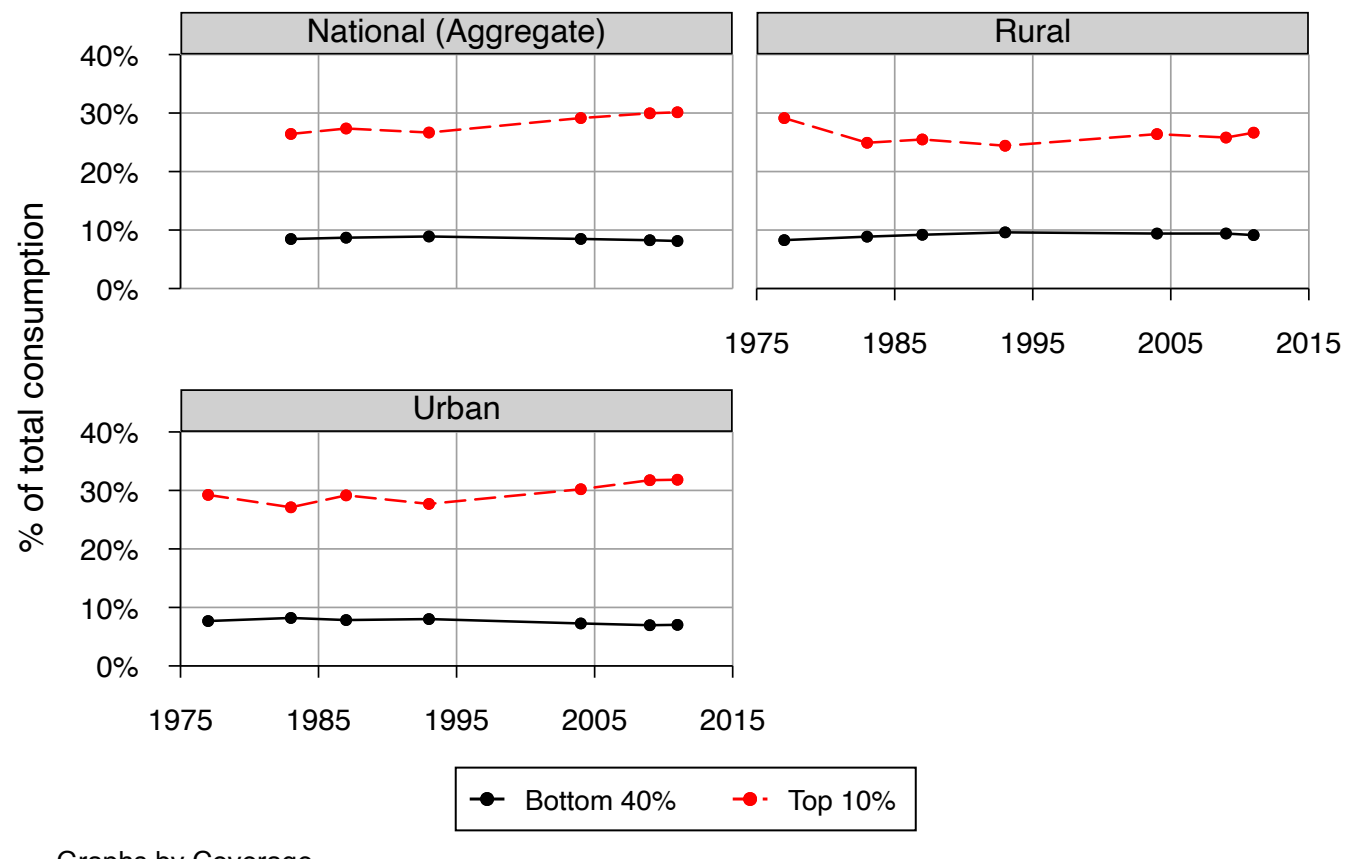

Graphs by Coverage

Figure 1: Consumption shares by type, India. Source: Povcalnet, World Bank

We summarize the long run (1983-2011) trend in consumption growth across class in Figure 2, following from Deaton and Dreze's previous findings. We plot-

\footnotetext{
${ }^{18}$ According to the UN population division, urban population (as a share of total) grew from 23
} to 31 percent over this period. 


\section{Growth incidence curves: 1983-2011}
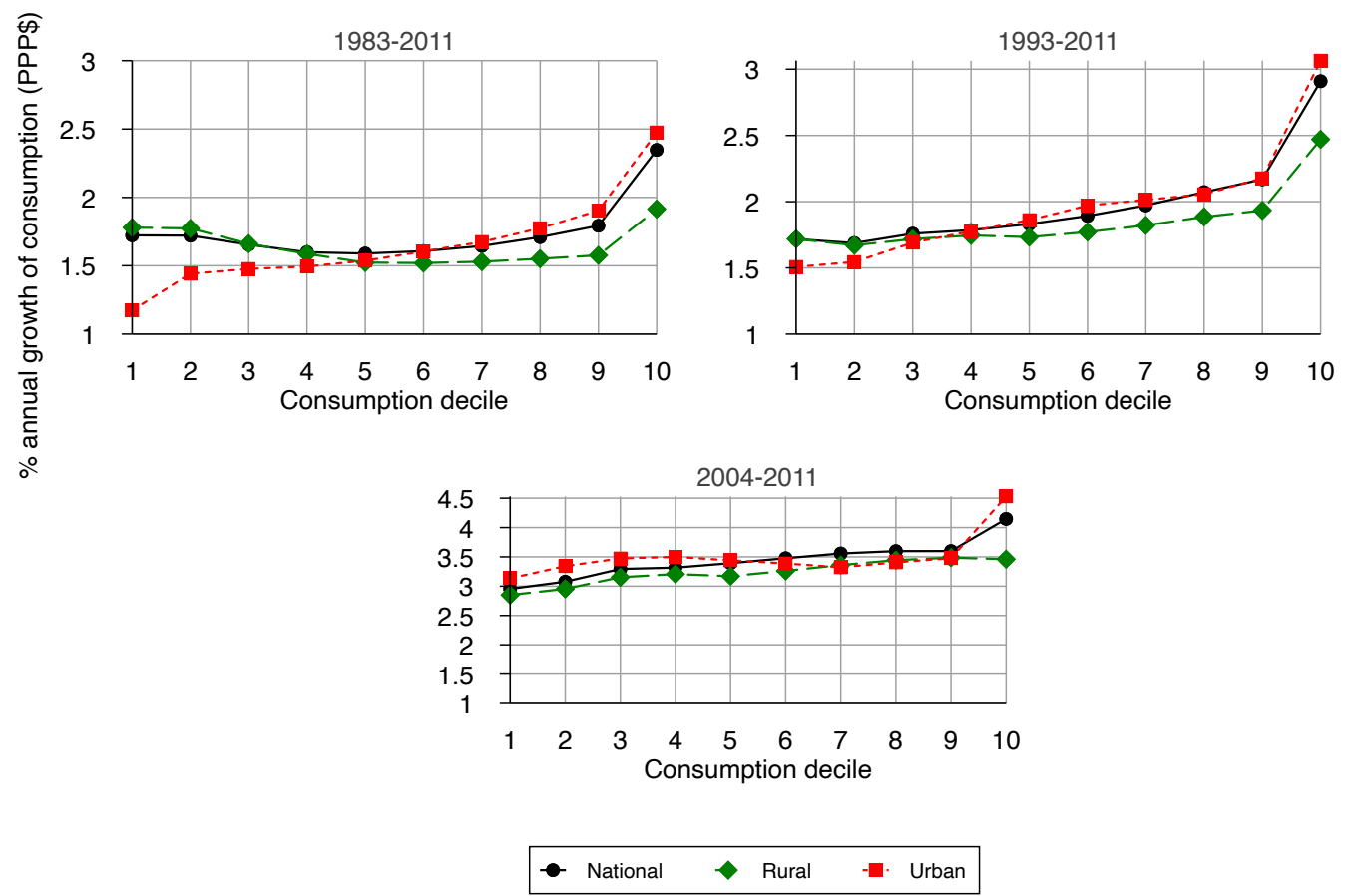

Figure 2: Growth incidence curve of consumption: 1983-2011

ted Growth Incidence Curves (GIC) for rural and urban India, besides the national aggregate. Each point represents growth in consumption ${ }^{19}$ for a fixed decile of the population, ranked within its respective sector. These data show that in the long run (1983-2011), there is substantial improvement in consumption for the lower rural deciles, potentially driving the national trend. However, progressively reducing the initial period, this increase fades away and gets overtaken by higher

\footnotetext{
${ }^{19}$ Note that the GIC is anonymous, in that we are not accounting for movement of individuals between deciles over time. Approaches towards computing the GIC vary depending on whether growth rates are calculated at the percentile level or as averages for the quantile group. We follow the latter method
} 
relative growth in the lower urban classes (2004-2011). Note that the 2004-2011 period is the fastest growth period where growth rates average over 3 percent per capita, compared to 1.5-2 percent over the extended period. Thus, the highest gains appear to have gone to the richest decile (throughout) and in more recent times, to the lower classes in urban India.

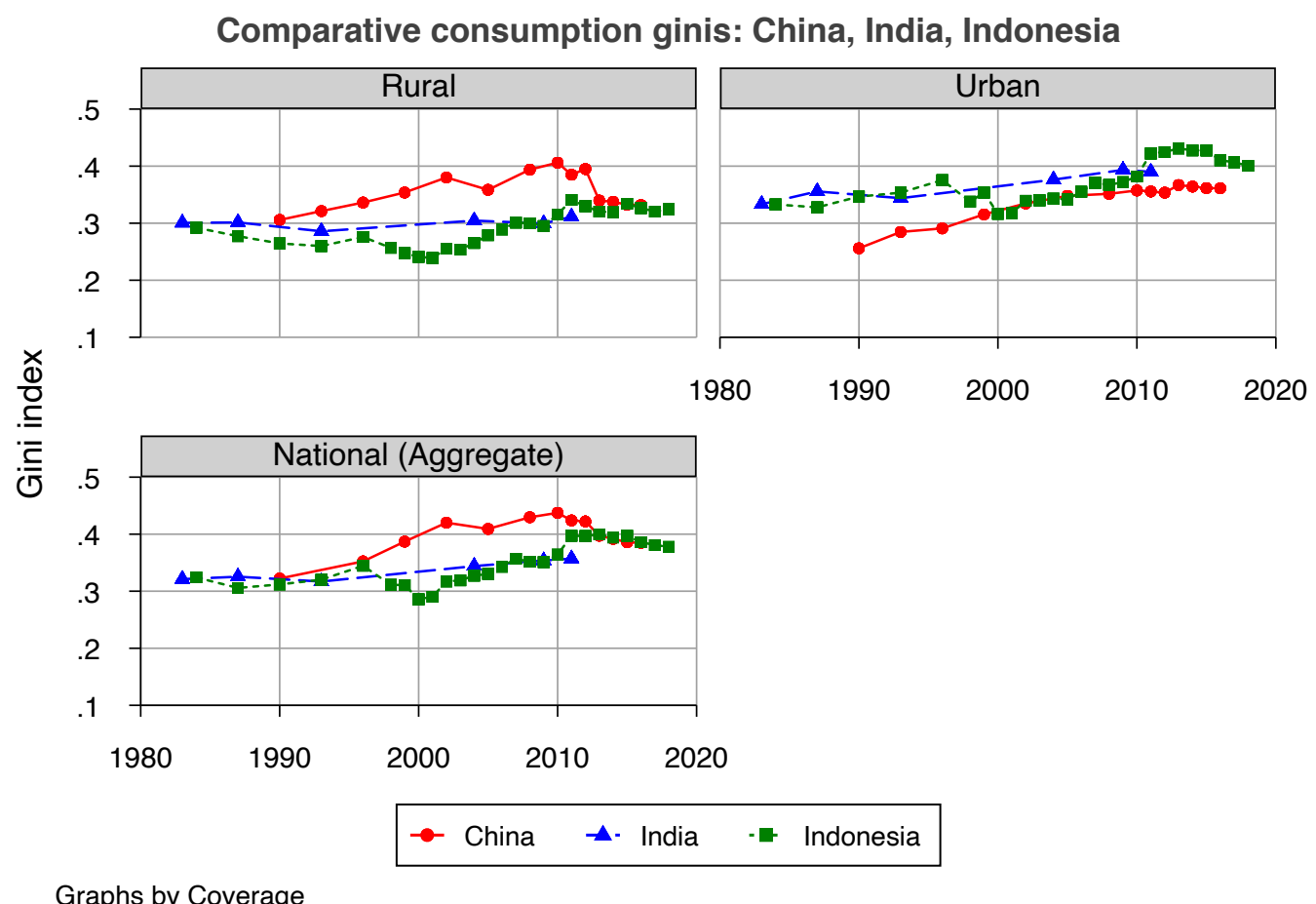

Figure 3: Ginis by type in India, China and Indonesia. Source: Povcalnet, World Bank

Next, in Figure 3 we compare inequality for each of these subregions using Gini indices, against similar data for China and Indonesia. Mainly, we compare to see if, how and why India's consumption inequality is different among the three 
largest emerging economies in Asia. The main feature here is that given less frequent data collection, and the trend itself, Indian inequality appears less dynamic (moving upward) relative to China and Indonesia. In the latter two countries, inequality actually appears to be coming down at the national level, after 2011. These three countries also differ in their sector specific trend - while India's rural Gini remained nearly flat over 1983-2011, China and Indonesia saw a sharp rise in rural consumption inequality over the same period. At the urban level, India's Gini demonstrated a rise (from 0.32 to 0.4 ), but the increase appears benign compared to the other two Asian economies; urban inequality in India was lower than Indonesia but higher than China in 2011. The last datapoint for India (2011) basically puts India's consumption inequality lowest among these three economies. Within the estimates as they currently exist, the Indian Gini appears distinct because its urban component drives the trend in the national aggregate. China and Indonesia's Ginis are dominated by trends in rural inequality. For example, Chinese decline in inequality mirrors its rural trend.

\subsection{Inter-state consumption and output}

Lastly, we address consumption inequality across states. Lamba and Subramanian (2020) noted a lack of convergence ${ }^{20}$ in per-capita state incomes - attesting to the stagnation of poor states hypothesis of Deaton and Dreze (2002) in the 1990s. We explicitly tested if consumption inequality (measured by the Gini coefficient) is

\footnotetext{
${ }^{20}$ We separately tested for convergence in Appendix C for the period 2004-2011 and confirmed no statistically significant relationship between state per-capita income growth and initial percapita income. A negative sign between these two variables would indicate convergence or "catchup."
} 


\begin{tabular}{lcccc}
\hline \hline & $(1)$ & $(2)$ & $(3)$ & $(4)$ \\
& Consumption Gini (0-100) & Consumption Gini (0-100) & Consumption Gini (0-100) & Consumption Gini (0-100) \\
\hline Log of state NDP per capita & 3.13 & 3.70 & $4.45^{* *}$ & $(1.72$ \\
& $(1.89)$ & $(2.26)$ & & $(1.88)$ \\
Agriculture & & 0.06 & & \\
& & $(0.12)$ & -0.13 & \\
Manufacturing & & & & \\
& & & & \\
Services & & & & 0.09 \\
& & & & \\
Constant & -2.08 & -9.23 & $-106)$ \\
& $(21.12)$ & $(26.34)$ & $(21.13)$ & -2.29 \\
\hline Observations & 32 & 32 & 32 & $(20.04)$ \\
Adjusted $R^{2}$ & 0.060 & 0.033 & 0.075 & 32 \\
\hline \hline Standard errors in parentheses & & & & 0.075 \\
${ }^{*} p<0.10,{ }^{* *} p<0.05,{ }^{* * *} p<0.01$ & & & & \\
\end{tabular}

Table 1: Inequality versus per-capita state GDP.

correlated to a state's per-capita income in 2011-12 (the year we analyze in the next section). For example, one potential hypothesis may be that rich states are also more unequal. In Table 1 we show that while the correlation is positive, it has no statistical significance at the 10 percent level. The only exception is when we control for manufacturing share of state GDP (column 3), the relationship become significant at the 5 percent level. Thus, outside of states with similar structural composition, state per-capita income, alone, is not a predictor of greater inequality; this is one important motivation for our use of state and sector combinations of location. 


\section{Variation in living standards in India: 2011-12}

Given the evolution of consumption until 2011-12, we now present our explanation of its variation based on location alone. Our framework is simple and compact by design: we plainly predict consumption levels based on (at most) two specific macro-variables which encapsulate the level of income, and distribution, in a location. Second, we are interested in the signs of those relationships (does inequality mean less or more consumption?). To be sure, the use of controls to account for individual circumstances would likely increase the precision of prediction - for example, a Mincer model to control for education and experience. This is not our aim and we deliberately abstain from socially relevant questions answered by others using this dataset; for example rising inequality between social groups (such as caste) (Kumar et al., 2019), inclusion (Bhalla, 2011) or inequality by type of consumption (food vs non-food) (Basole and Basu, 2015b). How important is location likely to be in terms of determining one's living standard in India? According to our decomposition of the Gini for 2011-12 consumption, 2-6 percent of differences between households are due to within-location inequality and $42-62$ percent of the differences ${ }^{21}$ are due to between-location inequality. The between-location component (62 percent) is higher and the main contributor to consumption Ginis when we divide states into substates (rural and urban) as a measure of location. On this basis, we try to analyze if location is a good predictor of consumption levels across the distribution.

\footnotetext{
${ }^{21}$ We used a Pyatt decomposition using the Stata program ineqdecgini. The rest of the differences are due to the residual due to overlap between consumption across groups.
} 
Our model is the same as the cross-country model in Milanovic (2015) except we explicitly focus on consumption ${ }^{22}$ while Milanovic tries to explains variation in income levels. In the same spirit of consistent cross-location comparison, we divide the population of every location into 100 percentiles, take the mean consumption in each percentile and use these percentiles as representative populations for consumption class. Accordingly, we can compare the 10th percentile in a rich state, to the 50th percentile in a less prosperous state. Thus, every location has the same number ${ }^{23}$ of observations in our analysis. Our specification considers the so-called "individual viewpoint" in that our regression is not weighted by the size of the population in different states and urban/rural locations. This model can be written as follows:

$$
C_{i j}=b_{0}+b_{1} S G D P p c_{j}+b_{2} G i n i_{j}+u_{i j}
$$

Here $C_{i j}$ is the log of consumption of percentile $i$ in location $j . S G D P p c$ is $\log$ of per capita GDP of the state - there is no further disaggregation available for GDP below the state level - and Gini $_{j}$ is the Gini coefficient of consumption in location $j$. We avoid using mean consumption, and instead use per capita GDP as our proxy for average living standards, because the coefficient $b_{1}$ would be biased towards 1 given our use of percentiles of consumption. The covariates basically test consumption distributions against two properties - mean income, and consumption inequality - which that location is "endowed" with, in the sense

\footnotetext{
${ }^{22}$ To be clear, Milanovic (2015) also uses consumption for India, China and Indonesia due to the same data constraints on income surveys we have mentioned earlier.

${ }^{23}$ In our more disaggregated comparison - at the level of rural and urban substates - we have less than 100 observations for some locations because of limited data.
} 
that an atomistic household (or even a percentile grouping of households) cannot possibly influence them on their own and has to take as a granted property. Both variables are independent of effort, specific circumstances and luck expended by a single representative unit in our formulation. Households may differ in their consumption for several reasons - gender, caste, education etc but we simply ask what premium is allocated to them ${ }^{24}$ because they happen to live in one region versus another.

An important factor to note here is that while Milanovic uses this equation at the global level, the fact that we focus on the Indian situation matters for (eventual) predictive power. The role of country-specific - or even region specific inequalities and differences may be very important in explaining within-country distributions of living standards. These differences may be diluted at the crosscountry level - for example, caste might matter a lot within India as an explanation of variation in consumption, but it does not matter that much at the world scale, and probably mean country incomes matter a lot more.

Our first model tests locational influence at the State level ( $j$ is a state), where with 32 states we have 3200 observations. Results are shown in Table 2. In Column 1 we present results from a regression run exactly in the form described in Eqq 1. This model explains 18 percent of variation in consumption. The coefficient on log of per-capita state GDP is positive, and statistically significant at the 1 percent level. Since consumption and per-capita state GDP are in log form,

\footnotetext{
${ }^{24}$ Additionally, while caste applies primarily to the 80 percent Hindu majority of India, the entire population can be said to have had location assigned to them.
} 
this coefficient is basically the elasticity of own consumption against the expected income of that state - around 45 percent. A positive sign is not surprising and simply says that richer states have higher expected living standards. Interestingly, the coefficient on the Gini is not statistically significant, meaning that one is not affected by how unequally consumption is distributed in that state. We used two further variants of this model, replacing $S G D P p c$ with state-level literacy rates (column 2) and manufacturing share of output (column 3), two good predictors of relative economic dynamism and prosperity (Amirapu and Subramanian, 2015). The coefficients on these proxies in both models are positive, delivering between 1-3 percent improvement in own consumption for a unit increase - although manufacturing only produces statistical significance at the 10 percent level. In both cases, $R^{2}$ drops (drastically, in case of manufacturing). Finally, we replace all the covariates and use only State dummies in a simple Least Square Dummy Variable (LSDV) model in column 4. This model produces a better fit than any of the previously used models, explaining 25 percent of variation in consumption. Ultimately, at this level, these results are straightfoward and locational inequality plays no role in expected consumption. Thus, the model simply shows basic incentive for migration to a rich state and exploiting the positive elasticity of state mean incomes (or their proxies) as a way of improving living standards.

We are more interested in exploiting the added variation in rural and urban consumption and their interaction with the rank ordering of states in terms of income levels. As already mentioned, if the population is grouped into substates ( $2 \mathrm{~N}$ locations for $\mathrm{N}$ states), then between group inequality is the main contributor to overall consumption inequality - larger than the residual, and much larger than the single 


\begin{tabular}{|c|c|c|c|c|}
\hline & (1) & (2) & (3) & (4) \\
\hline & Log of consumption & Log of consumption & Log of consumption & Log of consumption \\
\hline \multirow[t]{2}{*}{ Log of state NDP per capita } & $0.55^{* * *}$ & & & \\
\hline & $(0.07)$ & & & \\
\hline \multirow[t]{2}{*}{ State Gini $(0-100)$} & -0.00 & 0.01 & 0.02 & \\
\hline & $(0.01)$ & $(0.01)$ & $(0.01)$ & \\
\hline \multirow[t]{2}{*}{ Literacy Rate } & & $0.03^{* * *}$ & & \\
\hline & & $(0.01)$ & & \\
\hline \multirow[t]{2}{*}{ Manufacturing } & & & $0.01^{*}$ & \\
\hline & & & $(0.00)$ & \\
\hline \multirow[t]{2}{*}{ Constant } & $3.85^{* * *}$ & $7.50^{* * *}$ & $9.31^{* * *}$ & $10.51^{* * *}$ \\
\hline & $(0.67)$ & $(0.44)$ & $(0.28)$ & $(0.00)$ \\
\hline State dummy & No & No & No & Yes \\
\hline Observations & 3189 & 3189 & 3189 & 3189 \\
\hline$R^{2}$ & 0.181 & 0.116 & 0.031 & 0.254 \\
\hline \multicolumn{5}{|l|}{ Standard errors in parentheses } \\
\hline \multicolumn{5}{|l|}{ Std errors clustered at State level } \\
\hline${ }^{*} p<0.10,{ }^{* *} p<0.05,{ }^{* * *} p<0$. & & & & \\
\hline
\end{tabular}

Table 2: State level regression

digit contribution of within-group inequality. In our second specification we divide our data further. Each percentile of consumption is now $C_{i j k}$ where $k$ takes on the values 1 (rural), 2 (urban) for a total of 200 percentiles per state (100 urban, 100 rural) and 6400 (200 percentiles for each of 32 states) total observations. $S G D P p c$ still enters at the State level but the variable $G i n i_{j}$ is now Gini $_{j k}$ thus representing inequality in the rural or urban part $(k)$ of the State $\mathrm{j}$. Therefore, our model now tries to explain consumption by testing against income levels at the state, and the degree of inequality in rural and urban parts of the state. 


\begin{tabular}{|c|c|c|c|c|}
\hline & (1) & (2) & (3) & (4) \\
\hline & Log of consumption & Log of consumption & Log of consumption & Log of consumption \\
\hline \multirow[t]{2}{*}{ Log of state NDP per capita } & $0.40^{* * *}$ & & & \\
\hline & $(0.05)$ & & & \\
\hline \multirow[t]{2}{*}{ State-Sector Gini (0-100) } & $0.02^{* * *}$ & $0.03^{* * *}$ & $0.03^{* * *}$ & \\
\hline & $(0.00)$ & $(0.00)$ & $(0.01)$ & \\
\hline \multirow[t]{2}{*}{ Literacy Rate } & & $0.02^{* * *}$ & & \\
\hline & & $(0.00)$ & & \\
\hline \multirow[t]{2}{*}{ Manufacturing } & & & $0.01^{* *}$ & \\
\hline & & & $(0.00)$ & \\
\hline \multirow[t]{2}{*}{ Constant } & $4.79^{* * *}$ & $7.49^{* * *}$ & $8.99^{* * *}$ & $10.31^{* * *}$ \\
\hline & $(0.54)$ & $(0.37)$ & $(0.19)$ & $(0.00)$ \\
\hline State dummy & No & No & No & Yes \\
\hline Observations & 6114 & 6114 & 6114 & 6114 \\
\hline$R^{2}$ & 0.177 & 0.152 & 0.101 & 0.312 \\
\hline \multicolumn{5}{|l|}{ Standard errors in parentheses } \\
\hline \multicolumn{5}{|l|}{ Std errors clustered at State level } \\
\hline${ }^{*} p<0.10,{ }^{* *} p<0.05,{ }^{* * *} p<0$ & & & & \\
\hline
\end{tabular}

Table 3: State-sector level regression

Results from this variation on the data are shown in Table 3. The first column shows the model estimated against state per-capita income and consumption inequality, with almost same $R^{2}$ as the old specification (17-18 percent). The main difference in this version is that both covariates are now strongly significant at the 1 percent level - thus we establish a relationship also between consumption and consumption inequality by location. Elasticity of own consumption state percapita GDP is slightly lower (40 percent) than the previous model, though still positive. Interestingly, the relationship between substate consumption Gini and own consumption is a positive relationship. Our estimate shows that a 1 point in- 
crease in the Gini increases expected own consumption by 3 percent - controlling for mean incomes at the state level, more unequal locations produce (on average) better expected living standards for its residents. When we ran proxies for state per capita income (columns 2 and 3) our estimates retained the positive sign on consumption inequality while producing the same signs on literacy rate and manufacturing share of output with noticeable loss in fit. All proxies are significant at least at the 5 percent level.

As these specifications show, own consumption gain from a one point increase in locational inequality is slightly higher ( 3 percent) than the gain from literacy or manufacturing shares (at the state level). These results point to the size of the urban-rural gap - strong enough to sway the result away from potential downward consumption pressure for most households that would be expected from higher inequality. Finally, we tested the location premium again as shown in column 4, with the substate location model explain 31 percent of variation in consumption. Therefore, our definition of location by itself explains nearly a third of the variation in consumption - better than structural predictors of inter-state differences such as human capital and industrialization. The coefficients (suppressed here) represent again the location premium of residing in a location, relative to the omitted substate which we set as rural Chhattisgarh (the poorest). These premiums are between 10-80 percent for almost all rural substates but over 150 percent for the richest urban substates. An interesting example is Delhi, which due to being a small region, has overlap between its urban and rural regions. The location premium on both rural and urban parts of Delhi is over 180 percent. 


\subsection{Living standards and inequality: a Kuznets process?}

The most interesting finding in our analysis is the positive relationship between own consumption and locational inequality. We obtained the same outcomes ${ }^{25}$ when we ran our state-sector regression for each decile of the population. Whether one considers the top or bottom decile, locational inequality predicts higher own consumption. The positive sign on $b_{2}$ (Eqq 1) appears paradoxical, and certainly different, to Milanovic's finding which showed that for the entire world, on average, locational inequality reduces living standards (Milanovic, 2015). Since there are many rich countries, with the level of inequality varying from high (USA) to low (Nordic countries), income level and inequality can be substituted because a person might gain more from being placed in the country whose distribution is "tighter" around the mean (i.e less unequal). For example, a person who expects to be in the lower half of the distribution of a more unequal country might end up far below the mean income/consumption.

One possible explanation of consumption increasing with locational Ginis, as we showed in our model, is an ongoing Kuznets process. Kuznets (1955) famously linked inequality and economic development, with the latter increasing initially with per-capita income and then declining to give the inverted U-shaped Kuznets curve. This first phase (pre-turning point) of this process depends on urban areas

\footnotetext{
${ }^{25} \mathrm{We}$ ran these regressions for each decile and found positive income elasticity and gains from locational inequality. The coefficient on inequality goes up as we move up on consumption class, meaning that the rich benefit more from locational inequality than the poor. However, the estimated coefficient is statistically significant for all ten deciles, ranging from around 0.7 percent for the poorest decile, to 6 percent for the richest decile. These tables are available from us on request
} 
being richer and also more unequal. Over time, as the urban sector absorbs rural population, the share of population that is allocated higher incomes/consumption goes up simultaneous to increasing weight of the more unequal region. Accordingly, structural change creates a tradeoff between relative and absolute living standards. For example, a person in the rural middle class can do little to change the mean consumption in their state of residence. With large enough gaps between the urban and rural sector, the more realistic option of gaining in consumption is to "migrate" to another distribution, where expected living standards are unambiguously higher. This individual may end up below the median in the urban sector, but still gain in terms of absolute consumption.

For India, we do not consider the second phase which follows the turning point and where inequality decreases in per-capita income for three reasons. First, as we showed previously, the trend in aggregate and urban inequality is upward for the period we consider. Second, India is still under-urbanized and has few large cities relative to other economies of its size (Chauvin et al., 2017). Finally, spatial differences have shown no sign of closing - for example, Lamba and Subramanian (2020) find no evidence of convergence ${ }^{26}$ in per-capita state incomes.

Our main regression results should be understood as a cross-sectional snapshot of an ongoing Kuznets process. Given that our main model (states and sectors) creates two sectors within the same state, we essentially control for state per-capita

\footnotetext{
${ }^{26} \mathrm{We}$ also tested the convergence hypothesis during the most rapid period of economic growth (2004-2011) in Appendix C Table 5. In this case, we regressed growth rate of per-capita GDP on initial levels of per-capita GDP and found no statistically significant relationship without, or without controls for structural composition.
} 
income and test the implications of sector inequality for own consumption. In this case, the prediction of higher consumption in the more unequal location fits with the mechanism in Kuznets' hypothesis. As we showed in our state level model (Table 2), inequality at the state level alone was insignificant to own consumption; sectors matter. But there are also large differences between the sectors or rich and poor states. We next analyze two facets with the goal of underlining absolute and relative tradeoffs: the national distribution of consumption by sector and the distribution of consumption in rich versus poor states.

\subsection{Implications of the consumption distribution}

We first consider the probability distribution of rural and urban consumption. For this, we divided the respective populations of both sectors into 100 representative percentiles. This allows us to contrast classes at the percentile level without having to attach population weights (the urban sector is smaller). Kernel densities are shown in Figure 4. The basic summary is that the rural sector makes low consumption highly probable; the mode of rural consumption is to the left of the same for urban sector and peaks sharply. Now, we observe that the upper tail of the rural sector decays quickly in comparison to the bulk of the urban distribution. This gives rural consumption the property of being less unequal, but it also reinforces low consumption levels because the probability of "getting away" from the mode plummets in either direction. For the urban sector, the peak itself is dispersed widely but its placement intersects the upper tail of the consumption. Therefore, the vast majority of the urban population enjoys higher consumption than the rural population. To put numbers on these inter-sector differences, note the references lines shown in the figure. An individual just between the upper and lower half 


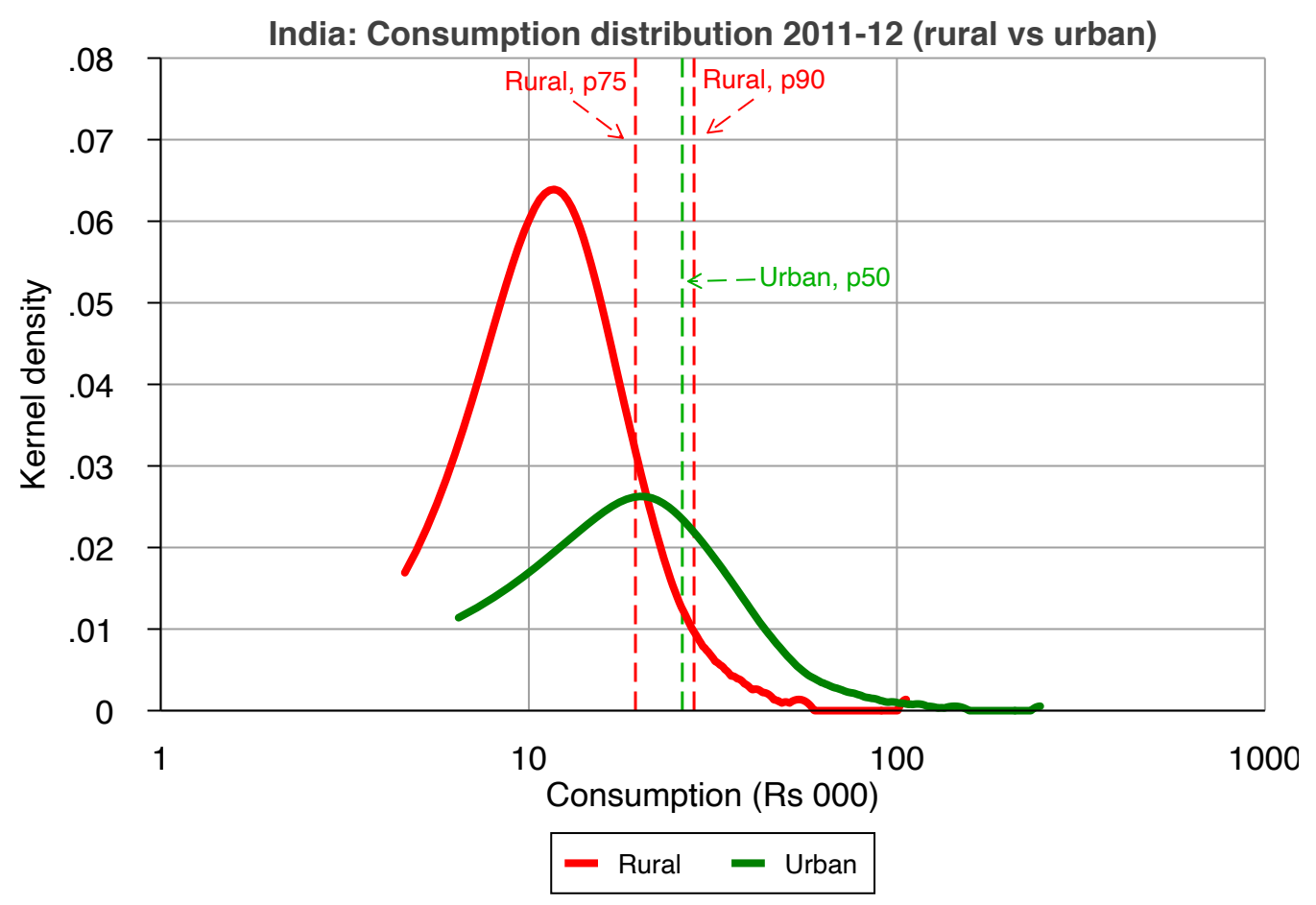

Figure 4: Kernel density of consumption: rural versus urban India.

of the urban distribution is placed at a living standard that is closer to the 90th percentile of the rural distribution. Or, put differently, this person is poorer than half the population in urban India, but richer in consumption than four-fifths of the population in rural India. In sum, the urban sector tends to give higher absolute living standards with much higher probability. One can be in the upper middle class in rural India, but still enjoy higher consumption as part of the lower middle class in urban India.

How do these sectoral differences vary across states? An important nuance here is that large urban areas are few; as we mentioned previously, India has few large 
(Kuznets type) cities, implying that opportunity is not unconditionally guaranteed by being allocated to an urban substate. There must be differences in rural distributions at the state level which also contribute to variation in consumption. We analyzed sector-wise kernel densities by state (the actual data underlying our regressions) and found ${ }^{27}$ heterogeneity in probability distributions for rich and poor states. Poor states have inexorably high peaks at a very low consumption level in the rural sector but consumption levels in their urban sector tends to be behind the national median ${ }^{28}$ as well. Rich states are mostly characterized by reclining (low-peaked) consumption densities in the urban sector, and often even in the rural sector.

To fix ideas on state-sector permutations we group states into the Top 5 richest (on the basis of per capita GDP) and the rest, and further divide each group into their respective rural and urban sectors. Then we plot consumption levels as a function of class for each of the 4 groups, with 100 representative percentiles per group. Figure 5 shows the result. We highlight two features: holding class constant, the urban sector in rich states dominates absolute consumption everywhere else; the opposite holds for the rural sector of poor states. However, the highest relative gain to consumption comes from moving from the rural to urban sector within poor states. This speaks to our aforementioned finding of low peaked consumption densities in rural and urban parts of rich states. The non Top 5 states,

\footnotetext{
${ }^{27}$ See Figure 6 in Appendix A

${ }^{28}$ The poorest states - Assam, Arunachal Pradesh, Bihar, Chhattisgarh, Uttar Pradesh, Madhya Pradesh, Manipur and Orissa - which include the most populous (Uttar Pradesh), account for most urban poverty in India. See Yenneti et al. (2017)
} 


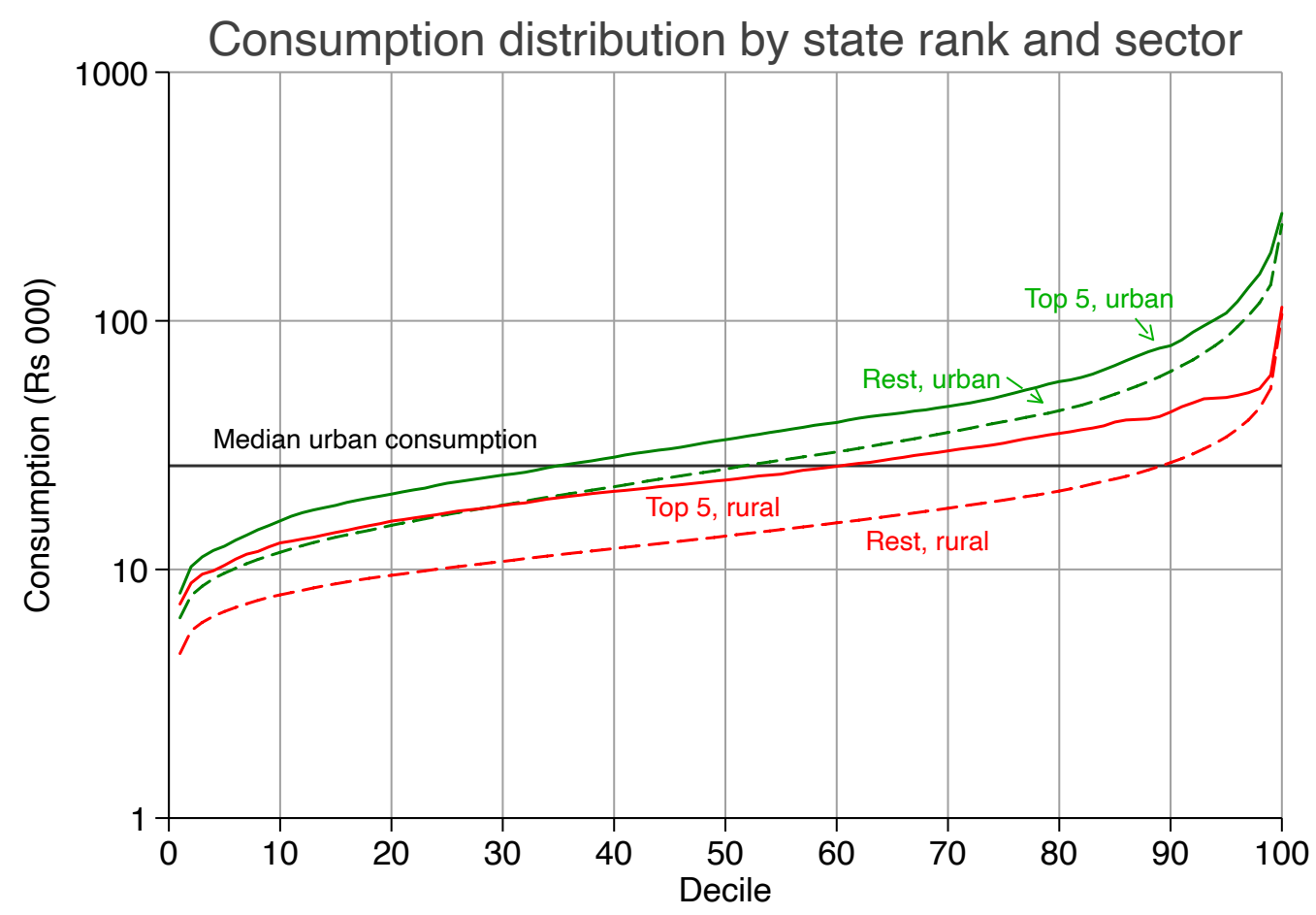

Figure 5: Consumption distribution in the richest 5 states vs the rest (only states with more than a million residents).

therefore, are the key driver of the positive relationship between inequality and own consumption - the urban sector in the non Top 5 states is the most unequal with a Gini of 0.39 (compared to 0.38 in the Top 5). Because our regression weighs every state equally (100 percentile per sector), the fact that the non Top 5 states are more numerous carries more weight in the analysis. Finally, we do not see any overlap in consumption and class across groups, barring a small amount below the 30th percentile of the rural and urban sector of the Top 5 and non Top 5 states, respectively. The presence of such overlap across these groups would 
indicate that the role of location depends on class - for instance, being poor is minutely better than in the rural sector of the Top 5 states than the urban sector of the other states. In general, the urban sector dominates rural sectors and rich states dominates poor states within sectors.

We note that the importance of location for consumption is emphasized further by the fact that it is not universal to other measures of prosperity, such as wealth. We ran a similar regression ${ }^{29}$ to the substate model, replacing consumption with household wealth for the same year (2011-12) using data from NSSO AIDIS survey. We found positive elasticity of state per-capita income on own wealth, but the relationship between wealth and locational wealth inequality ${ }^{30}$ was insignificant. Further, the LSDV model of location dummies only explains 10 percent variation of wealth; significantly less than the case for consumption. Given that wealth takes time to accumulate, the role of inheritance and social factors is likely higher. In summary, one can increase their living standards (measured by consumption) quickly by moving to a rich and unequal part of India, but the same is not true ${ }^{31}$ of wealth.

\footnotetext{
${ }^{29}$ Table 4 in Appendix B shows our results in detail

${ }^{30}$ This result holds despite a large urban-rural wealth gap and urban inequality having contributed to rising wealth inequality (Vakulabharanam and Motiram, 2018).

${ }^{31}$ For instance, the urban poor might be able to get more opportunity in a large city but living hand-to-mouth, while probably better than rural poverty, likely also restricts the possibility of wealth accumulation. Access to housing was cited as a fundamental determinant of urban poverty in India (Yenneti et al., 2017)
} 


\section{Conclusion}

We showed that spatial differences in Indian living standards are large - the largest explanation of interpersonal consumption inequality in India when spaces are defined as substates. Our results suggest that while class might be an important determinant of consumption, location plays a very significant role. This is one potential explanation of the persistence of migration, and the sheer size of migrant stock. Consistent with a Kuznets process, these differences create a tradeoff between relative and absolute living standards.

To illustrate our point numerically, consider the following example: suppose we take an individual on the 10th percentile in rural Bihar (a poor state). Keeping their location fixed, and endowing them with a jump in class to the 60th percentile takes their consumption from Rs 7200 to Rs 12000. Now, we take another representative individual, already in 60th percentile of rural Bihar and relocate them to urban Delhi but allocate them down to the 10th percentile. This shift changes their consumption from Rs 12000 to nearly Rs 16000. Individuals cannot singlehandedly change the distribution and level of living standards in their location by

their own effort. Plausibly, they can apply effort to move up what is essentially an exogenously given distribution in their location. However, they can move to be allocated a different distribution, and the gains accruing from location premium are large enough to justify migration over expending the effort to improve one's class position. We leave the topic of differences in consumption due to location, controlling for social groups (caste, gender and religion) as a topic for important future research. 


\section{References}

Alvaredo, F., L. Chancel, T. Piketty, E. Saez, And G. Zucman (2018): World Inequality Report 2018, Belknap Press.

Amirapu, A. AND A. Subramanian (2015): "Manufacturing or services? An Indian illustration of a development dilemma," Center for Global Development Working Paper.

Asher, S., P. Novosad, And C. RAFKIN (2018): "Intergenerational Mobility in India: Estimates from New Methods and Administrative Data," World Bank Working Paper.

BAsole, A. AND D. BASU (2015a): "Fuelling calorie intake decline: Household-level evidence from rural India," World Development, 68, 82-95.

- (2015b): "Non-food expenditures and consumption inequality in India," Economic and Political Weekly, 43-53.

Bhalla, S. (2011): "Inclusion and growth in India: some facts, some conclusions," .

Chakrabarti, A. S., A. Chatterjee, T. Nandi, A. Ghosh, And A. Chakraborti (2018): "Quantifying invariant features of within-group inequality in consumption across groups," Journal of Economic Interaction and Coordination, 13, 469-490.

Chancel, L. And T. Piketty (2019): “Indian Income Inequality, 1922-2015: From British Raj to Billionaire Raj?” Review of Income and Wealth, 65, S33S62. 
Chauvin, J. P., E. Glaeser, Y. MA, And K. Tobio (2017): "What is different about urbanization in rich and poor countries? Cities in Brazil, China, India and the United States," Journal of Urban Economics, 98, 17-49.

Datt, G., M. Ravallion, And R. Murgai (2020): "Poverty and growth in India over six decades," American Journal of Agricultural Economics, 102, 427.

Deaton, A. And J. Dreze (2002): "Poverty and inequality in India: a reexamination," Economic and political weekly, 3729-3748.

Deaton, A. And J. Drèze (2009): "Food and nutrition in India: facts and interpretations," Economic and political weekly, 42-65.

DeAton, A. AND V. Kozel (2005): "Data and dogma: the great Indian poverty debate," The World Bank Research Observer, 20, 177-199.

Deshrande, A. (2001): “Caste at birth? Redefining disparity in India,” Review of Development Economics, 5, 130-144.

Kumar, A. S., P. YAZIR, AND G. GopIKA (2019): “Consumption inequality in India after liberalization: A caste based assessment," The Singapore Economic Review, 64, 139-155.

KumAR, R. (2017): “'Two Class’ Distribution of Income in India,” Economic \& Political Weekly, 52, 59.

KuZnets, S. (1955): "Economic growth and income inequality," The American economic review, 45, 1-28. 
LAmbA, R. AND A. Subramanian (2020): "Dynamism with incommensurate development: The distinctive Indian model," Journal of Economic Perspectives, 34, 3-30.

MilanOviC, B. (2015): "Global inequality of opportunity: How much of our income is determined by where we live?" Review of Economics and Statistics, $97,452-460$.

Munshi, K. And M. RosenzWeig (2009): "Why is mobility in India so low? Social insurance, inequality, and growth," Tech. rep.

Pandey, B., M. Reba, P. Joshi, And K. C. Seto (2020): “Urbanization and food consumption in India," Scientific reports, 10, 1-12.

Somanchi, A. (2021): "Missing the Poor, Big Time: A Critical Assessment of the Consumer Pyramids Household Survey," .

Subramanian, S. (2011): "The poverty line: Getting it wrong again," Economic and Political Weekly, 37-42.

Subramanian, S. AND D. JAYARAJ (2015): "Growth and Inequality in the Distribution of India's Consumption Expenditure: 1983 to 2009-10,” Economic and Political Weekly, 39-47.

Sundaram, K. AND S. D. TENDUlKaR (2003): "NAS-NSS estimates of private consumption for poverty estimation: A further comparative examination," Economic and Political Weekly, 376-384.

Topalova, P. (2007): “Trade Liberalization, Poverty and Inequality: Evidence 
from Indian Districts," in Globalization and Poverty, University of Chicago Press, 291-336.

VAKUlabharanam, V. AND S. Motiram (2018): "Role of urban inequality in the phenomenon of rising wealth inequality in India, 2002-2012," Social Development Report.

Yenneti, K., Y. D. Wei, AND W. Chen (2017): “The urbanization of poverty in India: Spatio-temporal disparities in consumption expenditures," Geographical Review, 107, 360-383. 


\section{Appendices}

\section{A State level kernel densities}
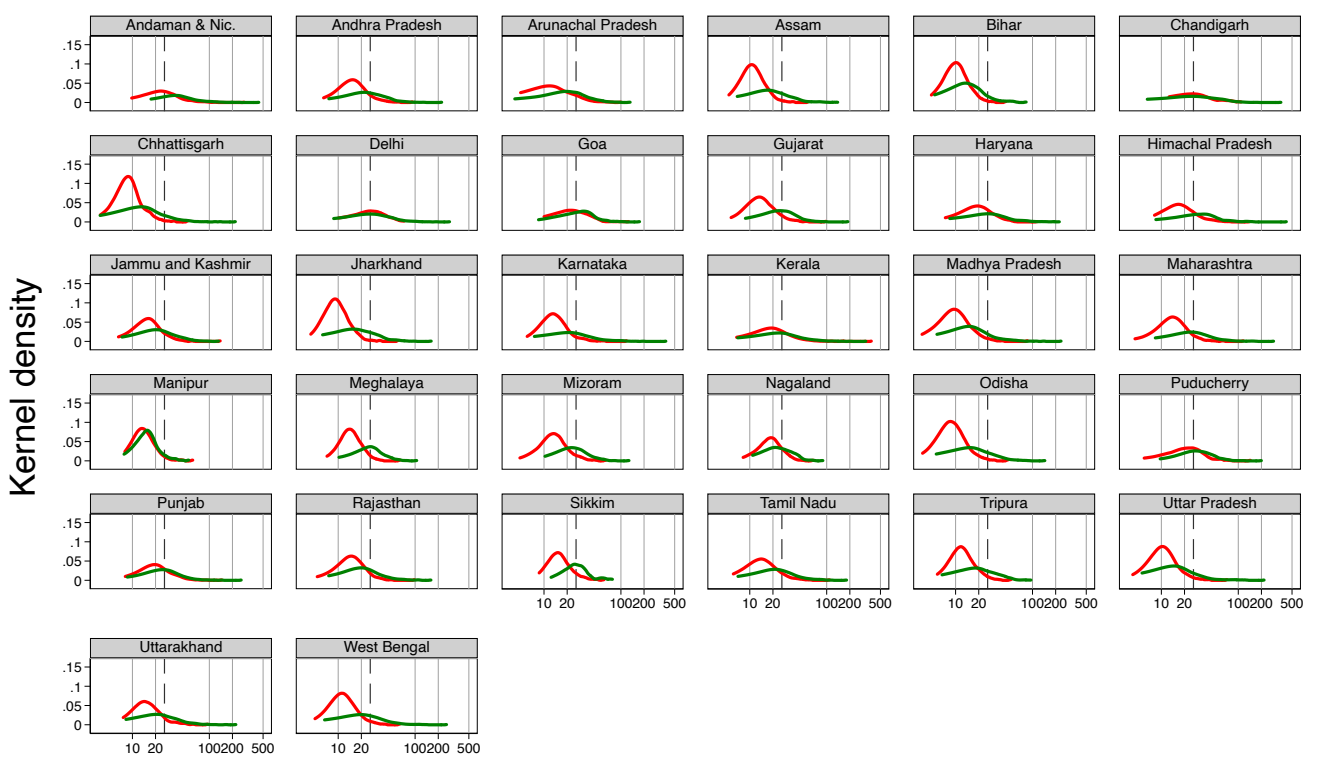

Consumption (Rs 000)

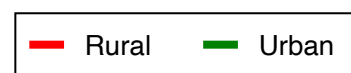

Dashed vertical line is national urban median

Figure 6: State wise kernel density of consumption: rural versus urban India. 


\section{B Location regression on wealth}

\begin{tabular}{lcc}
\hline \hline & $(1)$ & $(2)$ \\
& Log of wealth & Log of wealth \\
& $\mathrm{b}$ & $\mathrm{b}$ \\
\hline Log of state NDP per capita & $.3127327^{* *}$ & \\
State Gini (0-100) & .0037732 & \\
Constant & $8.453291^{* * *}$ & $11.66479^{* * *}$ \\
State-Sector dummy & No & Yes \\
\hline r2 & .0107759 & .1053952 \\
$\mathrm{~N}$ & 5861 & 5956 \\
\hline \hline
\end{tabular}

Std errors clustered at State-Sector level

${ }^{*} p<0.05,{ }^{* *} p<0.01,{ }^{* * *} p<0.001$

Table 4: State-sector regression of wealth on location 


\section{Growth rate and per-capita GDP at state level: 2004-2011}

\begin{tabular}{|c|c|c|c|c|}
\hline & (1) & (2) & (3) & (4) \\
\hline & Growth rate, 2004-2011 & Growth rate, 2004-2011 & Growth rate, 2004-2011 & Growth rate, 2004-2011 \\
\hline \multirow[t]{2}{*}{ Log, 2004, pc income } & -0.31 & -0.47 & -0.38 & -0.45 \\
\hline & $(0.86)$ & (1.13) & $(0.94)$ & $(0.81)$ \\
\hline \multirow[t]{2}{*}{ Agriculture , 2004} & & -0.01 & & \\
\hline & & $(0.07)$ & & \\
\hline \multirow[t]{2}{*}{ Manufacturing, 2004} & & & 0.02 & \\
\hline & & & $(0.07)$ & \\
\hline \multirow[t]{2}{*}{ Services , 2004} & & & & 0.01 \\
\hline & & & & $(0.04)$ \\
\hline \multirow[t]{2}{*}{ Constant } & 8.32 & 10.28 & 8.86 & 9.18 \\
\hline & $(9.30)$ & $(13.02)$ & $(9.78)$ & $(8.84)$ \\
\hline Observations & 32 & 32 & 32 & 32 \\
\hline Adjusted $R^{2}$ & -0.031 & -0.065 & -0.064 & -0.064 \\
\hline
\end{tabular}

Table 5: Economic growth (2004-2011) regressed on 2004 per-capita state GDP 